\title{
Rare Earth Recycling: Forecast of Recoverable Nd from Shredder Scrap and Influence of Recycling Rates on Price Volatility
}

\author{
H. M. Dhammika Bandara ${ }^{1} \cdot$ Mark A. Mantell $^{1} \cdot$ Julia W. Darcy $^{1}$. \\ Marion H. Emmert ${ }^{1}$
}

Published online: 27 May 2015

(C) The Minerals, Metals \& Materials Society (TMS) 2015

\begin{abstract}
This manuscript quantifies the recoverability of the rare earth (RE) element neodymium from shredder scrap during the next two decades and provides a forecast of recycling rates until 2034 based on these calculations. In combination with this forecast, an analysis of historical price and recycling trends for several critical (i.e., platinum group metals, zinc, tantalum, cobalt, antimony, and tungsten) and non-critical materials (i.e., tin, chromium, gold, and copper) results in general conclusions for the future price volatility of REs in dependence on expected recycling rates.
\end{abstract}

Keywords Rare earths recycling - Shredder scrap - Price volatility $\cdot$ Critical materials

\section{Introduction}

Rare earth (RE) elements are critically important for manufacturing modern materials in the United States and worldwide. Their applications span fuel-efficient vehicles,

Electronic supplementary material The online version of this article (doi:10.1007/s40831-015-0019-3) contains supplementary material, which is available to authorized users.

Marion H. Emmert

mhemmert@wpi.edu

1 Center for Resource Recovery and Recycling, Department of Chemistry and Biochemistry \& Department of Mechanical Engineering, Worcester Polytechnic Institute, 100 Institute Road, Worcester, MA 01609, USA energy-efficient lighting phosphors, alloys with improved workability, MRI contrast agents, nuclear reactor shieldings, and lasers [1]. Even though REs are not particularly rare (their static depletion index is 870 years) [2], currently operational mining and processing sites are highly localized in one country (China) [2]. Therefore, the 2010 [3] implementation of export restrictions by China had a significant impact on the price development of REs with prices rising from $\$ 80$ to $\$ 244$ for $1 \mathrm{~kg}$ of neodymium oxide within a year [4]. In light of a significant projected growth in demand for REs due to their use in renewable energy technologies and IT/telecommunication devices, $\mathrm{RE}$ availability has become a pressing concern in the United States and beyond [2].

Several strategies have been discussed to avoid future price spikes through diversifying the supply of REs, substitution of RE-containing materials $[5,6]$ as well as reuse [5] and recycling [7] of end-of-life RE-containing products. However, for one particular material application, $\mathrm{NdFeB}$ magnets in motors and generators, none of these approaches are currently used. Developing a feasible recycling process for the REs neodymium $(\mathrm{Nd})$ and dysprosium (Dy) is particularly urgent, since $\mathrm{NdFeB}$ magnets are not substitutable in motors without a loss in performance [8].

In this report, we provide a forecast for the amount of recoverable $\mathrm{Nd}$ from end-of-life motors from shredder facilities over the next 20 years. Based on historical data, we further investigate how recycling rates can influence the price development of critical materials $[6,9]$. The results of these analyses are expected to inform decisions about the time frame in which recycling will be commercially feasible as well as advise consumers of RE materials about realistic expectations for future price developments. 


\section{Methodology}

\section{Forecast of Recyclable Nd Content in Shredder Scrap Until 2034}

The described analysis does not take into account the potential future changes in the processing of end-of-life cars; as such, disassembly before shredding will not be discussed in detail.

Using minimum and maximum values for the $\mathrm{Nd}$ content in shredder feed (light duty vehicle/LDVs, household appliances, other sources) as described by us previously [10], two different scenarios were considered in our forecast for the next 20 years: (1) Hybrid vehicle (HEVs) and electric vehicles (EVs) are not shredded with conventional LDVs and household appliances and (2) HEVs and EVs are shredded with conventional LDVs and household appliances. This distinction is important to arrive at accurate conclusions due to the much higher Nd content of HEVs and EVs when compared to conventional vehicles [11].

Several significant variables that affect the final Nd content of these vehicles (Nd content in conventional vehicles; $\mathrm{Nd}$ content in HEVs and EVs; market penetration of HEVs and EVs; and Nd content in household appliances) have been approximated as detailed below for the years 2019, 2024, 2029, and 2034 (see SI for detailed calculations).

\section{Nd Content in Conventional LDVs}

The calculated average weight of conventional LDVs produced between 2004 and 2013 is $1834 \mathrm{~kg}$ [12]. This average weight was used in calculations for the weight of LDVs and was assumed to remain constant between 2014 and 2034.

The weight of Nd in conventional LDVs over time has been considered using two scenarios (a) the $\mathrm{Nd}$ content remains constant at $303 \mathrm{~g}$ per LDV [10] after 2013 due to a continuous high price of $\mathrm{Nd}$; or (b) the $\mathrm{Nd}$ content increases linearly until 2034, continuing the trend before 2014 [10]. These two approximations are illustrated in Fig. 1. The Nd content in conventional LDVs further depends on the age distribution of shredded LDVs, which have been approximated using previously documented age distributions of cars shredded in 1995 and 2007 [10].

\section{Nd Content in HEVs and EVs}

The weight of HEVs/EVs and the weight of Nd in HEVs/ EVs need to be approximated in order to arrive at the $\mathrm{Nd}$ content of ferrous scrap from HEVs/EVs. The weight of HEVs was assumed to be equal to the average weight $(1483 \mathrm{~kg})$ of the four highest selling HEV models in the U.S. (Toyota Prius, Honda Civic, Ford Focus and Chevy Malibu) [13]; similarly, the weight of EVs was assumed to

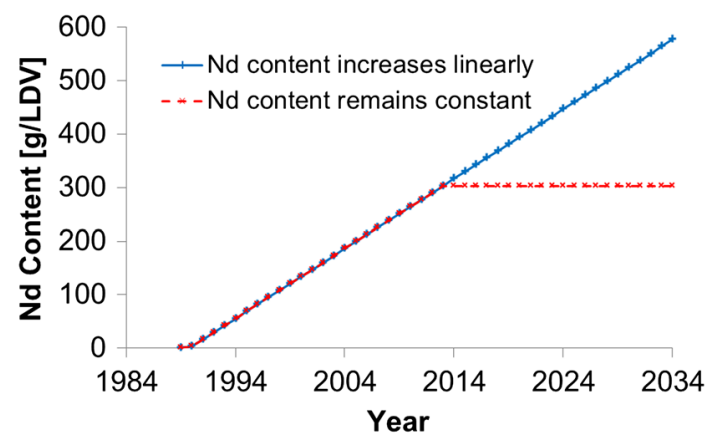

Fig. 1 Minimum ( $\mathrm{Nd}$ content constant; red) and maximum $(\mathrm{Nd}$ content increases linearly; blue) assumptions used to calculate the total weight of $\mathrm{Nd}$ in conventional LDVs

be equal to the average weight of $1570 \mathrm{~kg}$. These average weights of HEVs and EVs as well as the amount of $\mathrm{Nd}$ $(683 \mathrm{~g} \text { in HEVs; } 756 \mathrm{~g} \text { in EVs })^{2}$ after removal of the NiMH battery [14] are further postulated to remain constant until 2034 for two major reasons: First, the calculated average weights of the four most common models on the American market produced between 2009 and 2014 remained constant [15]; thus we assume a continuation of this trend. Second, even if lighter vehicles will be produced in the future, it is unlikely that such a weight reduction stems from reduction of functional, moving parts containing motors and Nd magnets. Thus, the overall Nd content of a vehicle per $\mathrm{kg}$ ferrous scrap might actually increase; therefore, our assumption of no change in vehicle weight and $\mathrm{Nd}$ content is indeed a conservative approximation.

\section{Market Penetration of EVs and HEVs}

Various forecasts of EV and HEV market penetration have been made and are illustrated in Fig. $2[16,17]$. The lowest market share of $8 \% \mathrm{HEVs} / \mathrm{EVs}$ in 2034 is predicted by the U.S. Energy Information Administration [16], which provides several reasons for its forecast. First, HEVs/EVs have higher purchase prices than conventional LDVs and are more fuel efficient during the time of ownership. Thus, more fuelefficient conventional LDVs, which are currently developed, and an expected rising price for electricity will result in consumers deciding against the purchase of HEVs/EVs. Second, battery technology is not expected to improve substantially in the near future with respect to battery cost, safety, and performance; all these elements would favor purchases of conventional vehicles.

In contrast, the highest market penetration of $81 \% \mathrm{HEVs} /$ EVs in 2034 is predicted by Breker and coworkers [17]. Breker's forecast considers the various beneficial impacts of EVs on the economy (lower oil imports, improved trade deficit, more jobs in battery industry, healthcare cost savings due to less pollution). Since this approach only predicts market shares until 2030, market shares were linearly 
(a)

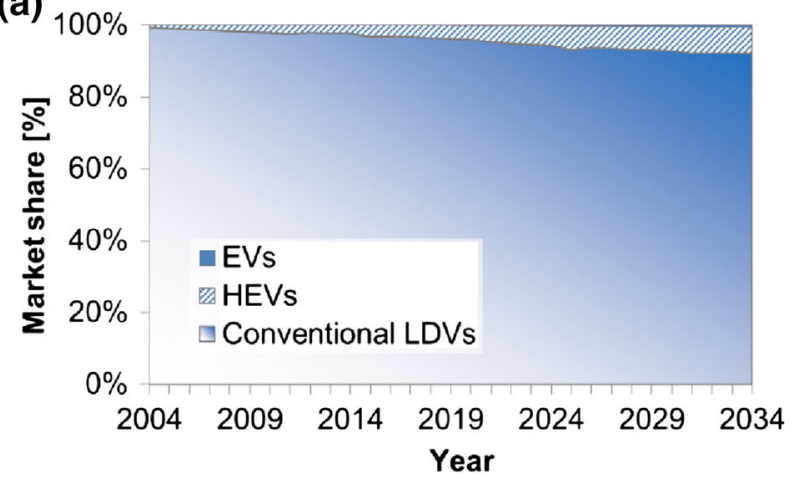

(b)

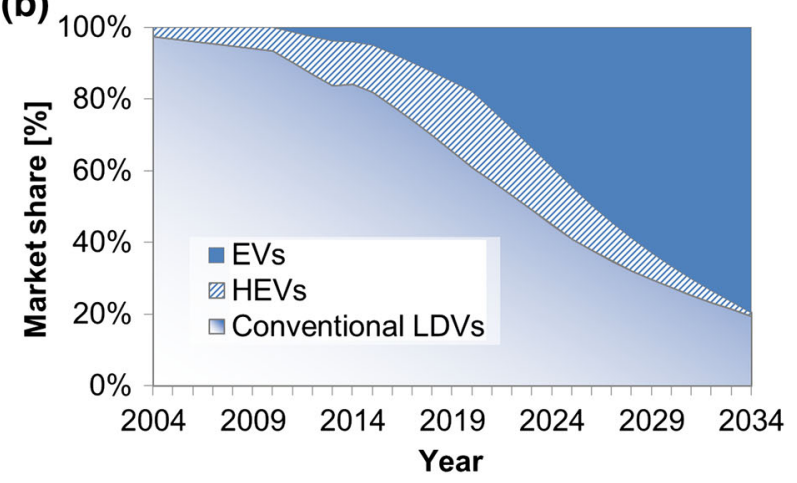

Fig. 2 a Minimum and $\mathbf{b}$ maximum market penetration of HEVs and EVs

extrapolated until 2034. Figure 2 graphically illustrates these minimum and maximum market penetrations of HEVs and EVs, which were used for our calculations.

\section{Calculating the Nd Content in LDVs}

As described in detail elsewhere [10], the $\mathrm{Nd}$ content in all LDVs (conventional LDVs, HEVs, and EVs) was calculated according to Eq. (1), using the variables $x_{v, i}$, the weight of $\mathrm{Nd}$ in ferrous scrap from shredding type $v$ LDVs manufactured in year $i, w_{v, i}$, the percentage of type $v$ LDVs manufactured in year $i, s_{v, i}$, the market penetration of type $v$ LDVs manufactured in year $i$, and $\bar{x}$, the average $\mathrm{Nd}$ content in ferrous scrap.

$\bar{x}=\frac{\sum w_{v, i} x_{v, i} s_{v, i}}{\sum w_{i}}$

$w_{v, i}$ and $x_{v, i}$ were calculated as described previously [10]; $s_{v, i}$ is the market penetration described above. All values for $x_{v, i}, w_{v, i}, s_{v, i}$, and $\bar{x}$ have been tabulated for the years 2014, 2019, 2024, 2029, and 2034 in the SI.

\section{Nd Content in Household Appliances}

The Nd content in household appliances was assumed to increase or stay constant at the same rate with which the $\mathrm{Nd}$ content in conventional LDVs increases or stays constant as assumed suggested by a prior analysis (see SI for detailed calculations) [18]. Calculations were performed using $0.70 \mathrm{~g}$ $\mathrm{Nd} / \mathrm{kg}$ ferrous as the maximum $\mathrm{Nd}$ content (as reported for U.K. appliances) $[10,19]$ and $0.61 \mathrm{~g} \mathrm{Nd} / \mathrm{kg}$ ferrous as the minimum $\mathrm{Nd}$ content (adjusted for major appliances) [10,20].

\section{Predicting the Influence of Recycling Rates on Price Volatility}

\section{Scope}

Initially, we surveyed all metals for which secondary production data are available through the United States
Geological Survey (USGS) [21]. These data are exclusively U.S. data, meaning that only U.S. prices and secondary production in the U.S. are analyzed. Our analysis focused on inflation-adjusted prices, as these prices are a better measure of real value than raw price data. The further below illustrated rate of secondary production for the analyzed metals is reported in percentages as the ratio of secondary production divided by the apparent consumption in the U.S. for the same year. Secondary production is defined differently for each metal [21], but in general is the creation of new metal from metal scrap. Apparent consumption is a calculation that takes into account primary and secondary production, imports, and exports. The apparent consumption totals are also calculated by the USGS. We treated secondary production rates as analogous to recycling rates, because secondary production rates compare the amount of new metal created from recycled scrap to the total amount used in the United States. Secondary production and apparent consumption data are both reported in metric tons per year and the axes scales are chosen to suit data and to align the zero points for both graphs; maxima of secondary production rate and inflationadjusted price in the relevant time period are set to $100 \%$.

Our study aims to examine the effect of one economic system's response to recycling in relation to its total usage of a material. While prices may be radically different in other markets, we aim to investigate the response of US markets to US recycling rates. Although our study will only analyze the recycling rate in the US, we postulate that the response would be analogous to the way other free markets could react to a locally changing recycling rate.

Our analyses of secondary production and price development focus on the time after 1939. We postulate, based on historical events (such as the first World War and the Great Depression), that the period of price-control during WWII (1939-1943) [22] can be used as a starting point for later price development in a free market, which is the focus of our analyses. This restriction focuses our analyses on modern and currently relevant economic conditions. 


\section{Determining Criticality}

Next, a criticality analysis was performed for each of the 16 metals with available data for secondary production, inflation-adjusted prices, and apparent consumption [21]. We did not consider data available for iron and steel as iron is not rare per se (iron is the fourth most abundant element in the earth's crust) [23]. Steel was not considered as it consists of a mixture of elements [24]; thus its price can depend on the criticality of each of its components.

The elements of the performed analyses were adopted from the U.S. Department of Energy Critical Materials Strategy (see SI) [6]. This analysis was necessary since the availability of data on secondary consumption is not a factor in previous studies. Based on this analysis, we concluded that $\mathrm{Co}, \mathrm{Zn}, \mathrm{Sb}, \mathrm{Ta}, \mathrm{W}$, and platinum group metals (PGMs, including Pt, Pd, Ir, Os, Rh, and Ru) [21] could be considered to be critical materials, while $\mathrm{Mg}, \mathrm{Al}$, $\mathrm{Cr}, \mathrm{Ni}, \mathrm{Cu}, \mathrm{Ag}, \mathrm{Sn}, \mathrm{Au}, \mathrm{Hg}$, and $\mathrm{Pb}$ were not deemed critical. In order to further elucidate the influence of recycling on price development, we tabulated historical events and the resulting change in price for all 16 metals (see SI). This was necessary as, to the best of our knowledge, other comparative and comprehensive analyses of a series of metals are not available in the prior literature, while more focused analyses (e.g., for Co and REs) are well documented $[6,25]$

\section{Price Volatility}

In our analyses of price volatility as discussed in the next sections, low price volatility was defined as a change in price of less than $25 \%$ of the overall maximum price during a decade. High price volatility was defined to exist when the price changes were larger than $25 \%$ of the overall maximum, inflation-adjusted price. As an example, Cobalt (Co) prices change between 20 and $100 \%$ of the maximum inflation-adjusted historical price during the 10 years between 1973 and 1983; during the two decades prior to 1973, the price of Co changes only between 14 and $28 \%$ of the maximum inflation-adjusted historical price [26]. The first scenario (1973-1983) is thus a period with high price volatility (and low price stabilization), while the latter examples (1953-1963 and 1963-1973) represent decades of low price volatility.

In order to elucidate how recycling rates influence the price of critical materials, we first analyzed the available literature on this topic, which is surprisingly limited. Kirchain and coworkers found through simulations that price volatility is more pronounced when recycling rates are low (25\% and lower) [27]. High recycling rates, in contrast, contribute to price stabilization [28]. Despite this prior computational study, the conclusion has not been verified using historical price and recycling rates. Therefore, we decided to analyze historical data for critical metals with a special consideration for the influence of recycling rates on price stability.

\section{Results and Discussion}

\section{Forecast of Recyclable Nd Content in Shredder Scrap Until 2034}

\section{Nd Content in Ferrous Scrap from LDVs}

Based on the assumptions described in detail in 2.1, we are able to provide a forecast for the $\mathrm{Nd}$ content in conventional vehicles in the next 20 years (Recycling Scenario 1; see Fig. 3). Furthermore, with our calculations considering the market penetration of HEVs and EVs, we can also predict the average $\mathrm{Nd}$ content in all vehicles in case shredder operators decide to shred HEVs and EVs together with conventional LDVs (Recycling Scenario 2; Fig. 3). Based on the these calculations, we can predict that the average $\mathrm{Nd}$ content in ferrous scrap from conventional LDVs will rise to $0.24-0.30 \mathrm{~g}$ Nd per $\mathrm{kg}$ ferrous scrap in 2034; the Nd content in ferrous scrap when all types of vehicles are shredded together will lie between 0.26 and $0.48 \mathrm{~g} \mathrm{Nd}$ per kg ferrous scrap by 2034. Since the market penetration of HEVs/EVs was low in 2014 (2.4\%) [16], the obtained values for the $\mathrm{Nd}$ content in 2014 (0.09-0.11 g Nd per kg ferrous scrap) are not different in both scenarios.

Another option for recycling (Recycling Scenario 3) will be the complete removal of the large traction motors and generator motors from $\mathrm{HEVs} / \mathrm{EV}$ s before shredding in order to process these RE rich materials in a separate process [11]. In this case, HEVs/EVs contain the same amount of $\mathrm{Nd}$ as conventional LDVs [2] and the values given for Scenario 1 are valid for calculations of Scenario 3.

\section{Nd Content in Ferrous Scrap from Household Appliances}

Based on the assumptions described in 2.1 , the $\mathrm{Nd}$ content in ferrous scrap derived from shredding household appliances can be predicted to contain $1.85-2.13 \mathrm{~g} \mathrm{Nd}$ per $\mathrm{kg}$ ferrous scrap by 2034 (Fig. 4).

\section{Nd Content in Ferrous Shredder Scrap}

With the values obtained in the calculations described above, the overall $\mathrm{Nd}$ content of ferrous shredder scrap can be calculated. Ferrous scrap is generally produced by shredding 40-80 \% LDVs, 15-50 \% household appliances, 


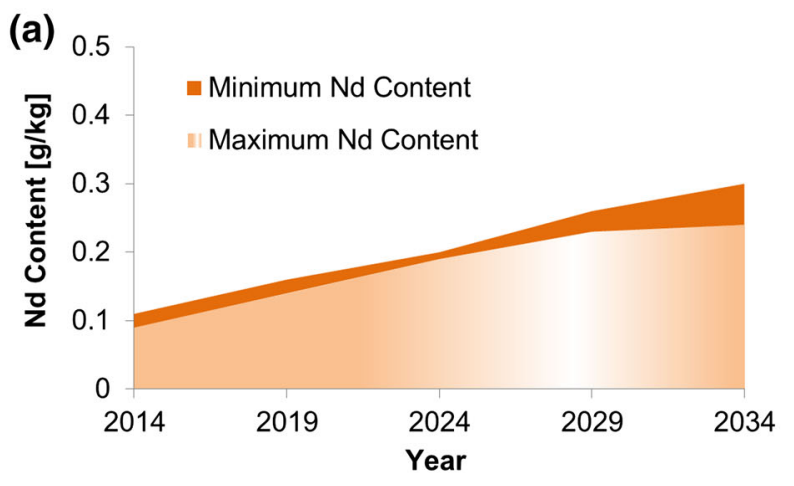

Fig. $3 \mathrm{Nd}$ content in a conventional LDVs compared to $\mathbf{b}$ all LDVs

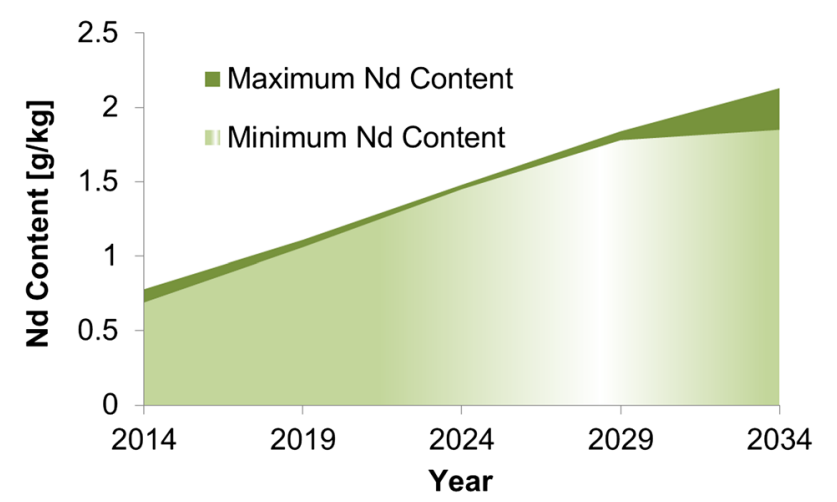

Fig. 4 Forecast of Nd content in household appliances

and $10-15 \%$ other sources (such as dismantled bridges or railroad cars) that do not contain $\mathrm{Nd}$ [10]; no change of these currently used ratios is expected for the next 20 years. Due to these ranges of materials in shredder feed that have been established previously in the literature and because of the high $\mathrm{Nd}$ content of household appliances and LDVs, the maximum $\mathrm{Nd}$ content in ferrous scrap can be expected when $10 \%$ of other sources, $50 \%$ household appliances, and $40 \%$ LDVs are used as shredder feed. In analogy, the minimum $\mathrm{Nd}$ content can be expected when using $15 \%$ other sources, $15 \%$ household appliances, and $70 \%$ LDVs [10].

Recycling Scenario 1 (no HEVs/EVs are shredded with conventional LDVs) and Recycling Scenario 2 (HEVs/EVs are shredded with conventional LDVs) are thus forecasted until 2034 (Fig. 5a, b). Interestingly, the numerical outcomes for $\mathrm{Nd}$ content in ferrous scrap in 2034 do not differ substantially $(0.33-0.89 \mathrm{~g} \mathrm{Nd} / \mathrm{kg}$ ferrous and $0.34-0.97 \mathrm{~g}$ $\mathrm{Nd} / \mathrm{kg}$ ferrous). This suggests that the effect of shredder feed composition (as detailed above) on the $\mathrm{Nd}$ content is more substantial than the effect of the different Recycling Scenarios 1 and 2. As such, the increase in the maximum $\mathrm{Nd}$ content over time mainly stems from the assumed increase of $\mathrm{Nd}$ content in household appliances.

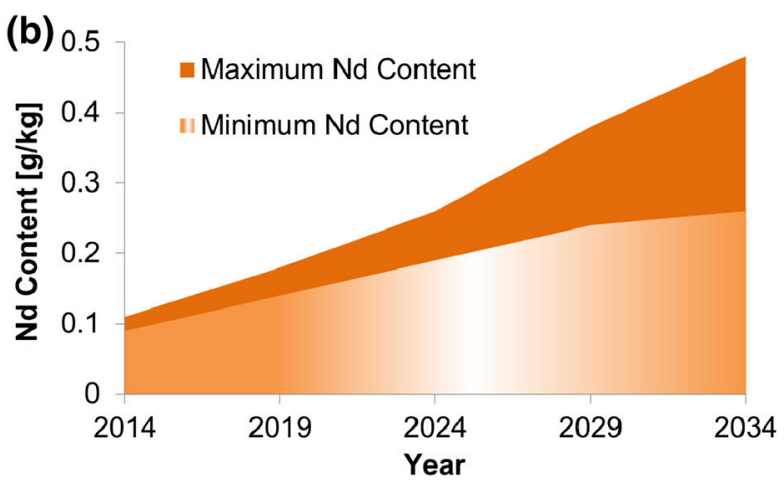

Figure $5 \mathrm{c}$ provides an overview of the predicted overall minimum and maximum $\mathrm{Nd}$ contents in shredder feed of all potential scenarios; furthermore, the same figure also provides average values for each year, as we find it likely that a combination of the different scenarios with regard to the different factors determining these values (co-processing of HEVs/EVs and conventional LDVs; shredder feed composition; market penetration of HEVs/EVs) will be realized. The increasing distance of the maximum and minimum values from the average values reflects the likely time-dependent growth of uncertainty for developments farther in the future.

\section{Maximum Recycling Rate for Nd in 2034}

The global demand for $\mathrm{Nd}$ in the next decade has been estimated previously by different groups [2,29]. With the assumption that the amount of ferrous scrap processed in the US will stay constant during the next decades [21], we can calculate that a minimum of $17,672 \mathrm{t}$ of $\mathrm{Nd}$ per year will be recoverable in 2034 from ferrous scrap at an assumed recovery rate of $70 \%$ [30]. ${ }^{1}$ This amount of $\mathrm{Nd}$ is equivalent to $14 \%$ of the global demand for $\mathrm{Nd}$ in 2034 [2]. In analogy to these calculations, we predict a maximum secondary production rate of $42 \%$ for the herein outlined Recycling Scenario 2 (see SI for details). To determine if and how these recycling rates might contribute to price stabilization, we will focus on determining the relationship between price developments and recycling rates in the next section using historical data for critical and noncritical materials.

\footnotetext{
1 The recovery rate is primarily dependent on the process that will be used and has been approximated as $70 \%$. This rate has been chosen based on the recent invention of a process [30] which allows for $80 \%$ recovery of $\mathrm{Nd}$ from scrap derived from shredding rare earth motors. Since this scrap derived from motors can be expected to have a higher $\mathrm{RE}$ content than ferrous scrap from shredding cars, the recovery rate was adjusted to a lower percentage in order to reflect the likely more challenging recovery.
} 

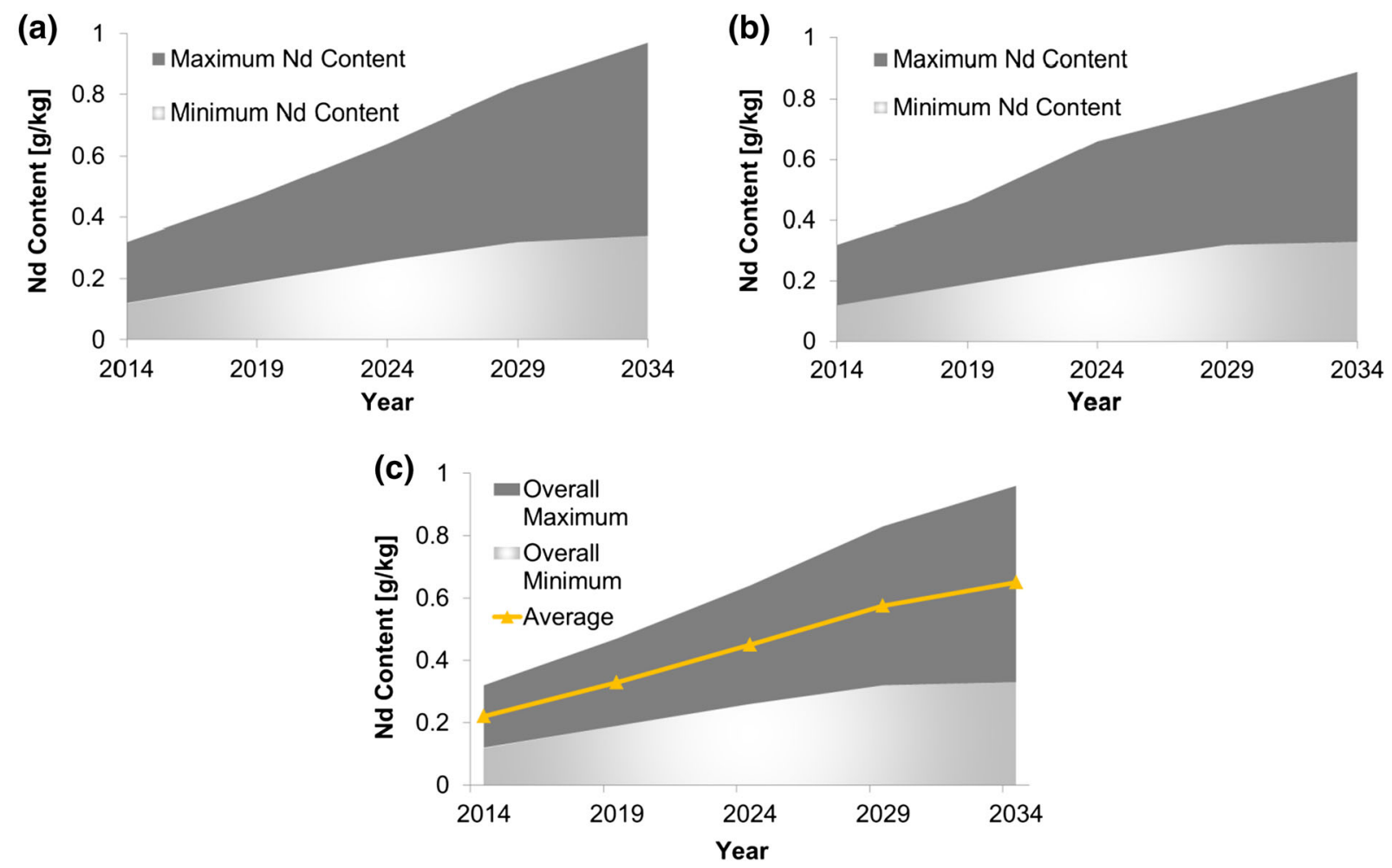

Fig. 5 Nd content in ferrous scrap. a Recycling Scenario 1: no HEVs/EVs are shredded with conventional LDVs. b Recycling Scenario 2: HEVs/EVs are shredded with conventional LDVs. c Overall minimum/maximum $\mathrm{Nd}$ content for all scenarios and

\section{Influence of Recycling Rates on Price Stabilization of Critical Materials}

As detailed above ("Predicting the influence of recycling rates on price volatility" section), historical secondary production rates as defined by the ratio of secondary production and apparent consumption [21] are only available for six critical materials: $\mathrm{Co}, \mathrm{Zn}, \mathrm{Sb}, \mathrm{Ta}, \mathrm{W}$, and PGMs. These six materials can be further differentiated with regard to their recycling rates [27]: (i) critical materials with only low recycling rates $(<25 \%)$, which include PGMs, $\mathrm{Zn}, \mathrm{Ta}$, and Co and (ii) critical materials with low $(<25 \%)$ and high $(>25 \%)$ recycling rates $(\mathrm{W}, \mathrm{Sb})$.

\section{Price Development of Critical Materials}

Figure 6 illustrates the correlation of inflation-adjusted price development versus the secondary production rates for critical materials. All values are shown between 1939 and the latest year for which both inflation-adjusted price data and secondary production totals are available from the USGS [21]. PGMs (6a), Zn (6b), Ta (6c), and Co (6d) exhibit a secondary production rate of consistently lower than $25 \%$ after 1939; for $\mathrm{Sb}(6 \mathrm{e})$ and $\mathrm{W}$ (6f), secondary progression of intermediate values. The intermediate values have been obtained by calculating the average between the overall minimum and overall maximum values for $\mathrm{Nd}$ content

production rates higher than $25 \%$ are observed for some time frames.

Interestingly, the maximum overall price of a material does not deviate substantially from the first price spike, a phenomenon that has been associated in the literature with a material "becoming critical" $[6,31]$. These initial price spikes can be seen in 1974 for PGMs, in 1951 for Zn, in 1979 for Ta, in 1979 for Co, in 1970 for Sb, and in 1956 for W. Another remarkable feature of the graphs in Fig. $6 a-d$ is the price volatility, ranging between 11 and $100 \%$ of the inflation-adjusted price during the illustrated time periods. The price volatility seen in Fig. 6e, $\mathrm{f}$ is analogous during times of low secondary production (1993-2012 in 6e for $\mathrm{Sb} ; 1956-1990$ in $6 \mathrm{f}$ for $\mathrm{W}$ ) with prices between 10 and $78 \%$. However, during times of high secondary production rates (1943-1967 in 6e for Sb; 1994-2005 in 6f for W), less price volatility can be seen as characterized by prices ranging mostly under $50 \%$ of the highest inflation-adjusted price $(25-43 \%$ of the inflation-adjusted maximum price for $\mathrm{Sb}$ between 1943 and 1967; 19-40\% for W between 1994 and 2005).

Based on these data, we suggest in agreement with prior computational investigations [27] that recycling can contribute to the price stabilization of critical materials, in 

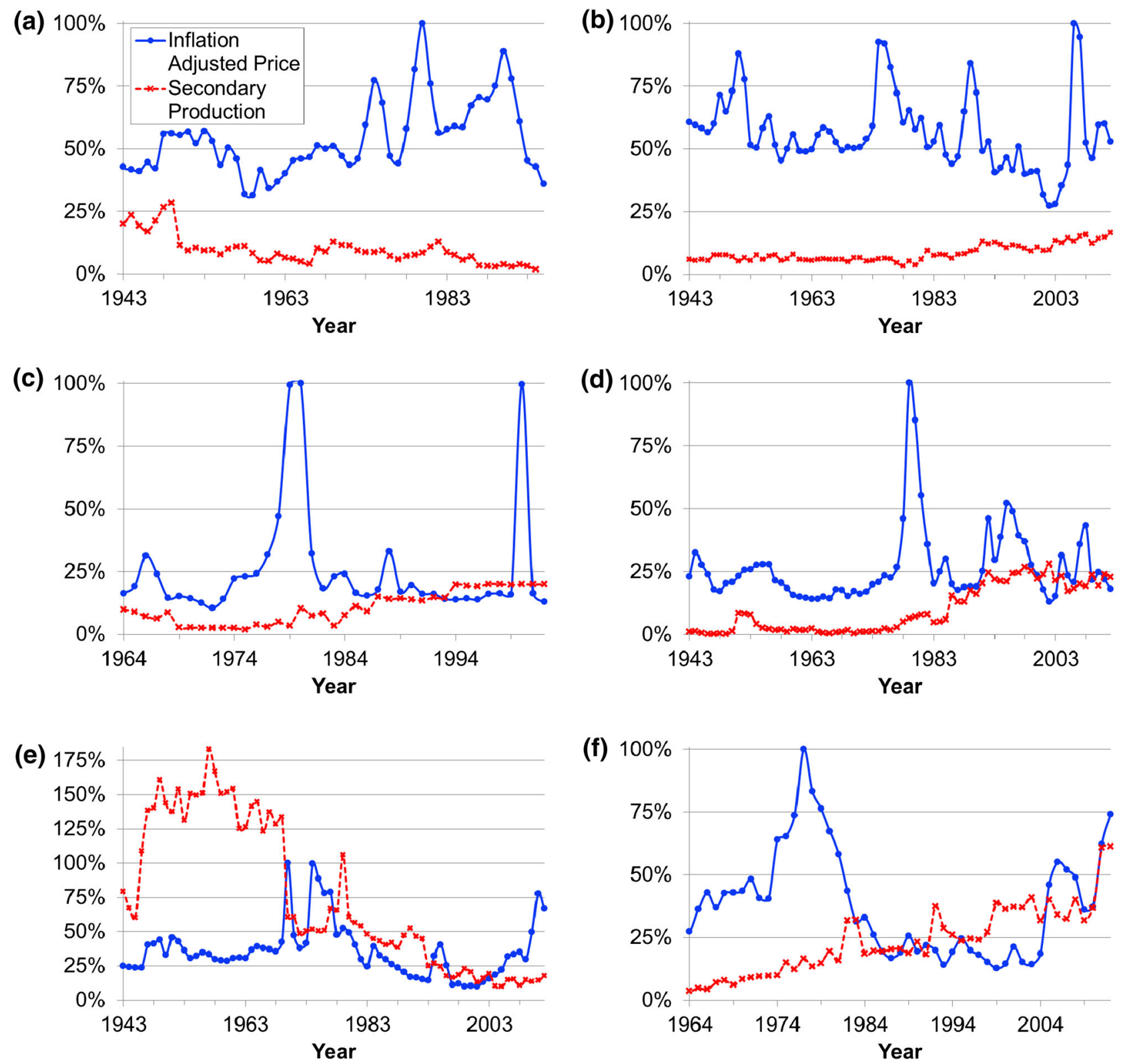

Fig. 6 Inflation-adjusted price versus secondary production rate for critical materials after 1939. a PGMs; b Zn; c Ta; d Co; e Sb; f W

particular, when recycling rates are high. However, prices are still expected to respond to geopolitical stimuli. This effect can not only be observed in the case of W (Fig. 6f) with relatively high secondary production rates (37-61 \%) between 1992 and 2006, but also clear rises in the price development, which can be rationalized by the unprecedented growth of the Chinese economy [26].

\section{Price Development of Non-critical Materials}

Next, we performed an analogous analysis of the four materials $\mathrm{Sn}, \mathrm{Cr}, \mathrm{Au}$, and $\mathrm{Cu}$ (Fig. 7a-d) in order to investigate if the above described price developments are similar for non-critical materials. Interestingly, no clear commonalities can be observed for the non-critical datasets. Sn pricing (Fig. 7a) behaves in analogy to the critical materials price development discussed above with a consistently low rate of secondary production between 1949 and 2012, resulting in large price differences (12-100\%) during the same period. However, a low secondary production rate below $25 \%$ (1952-2012) for $\mathrm{Cu}$ (Fig. 7d) only results in mild price volatilities between 16 and $69 \%$. The secondary production rates for $\mathrm{Cr}$ (Fig. $7 \mathrm{~b}$ ) and $\mathrm{Au}$ (Fig. 7c) seem to correlate with the price developments in many events (e.g., 1993-2003 and 2006-2012 for Cr; 1964-1990 and 2006-2012 for Au), while in other periods (e.g., 1962-1993 for Cr; 1990-2006 for Au) price volatility and secondary rate do not show any recognizable 


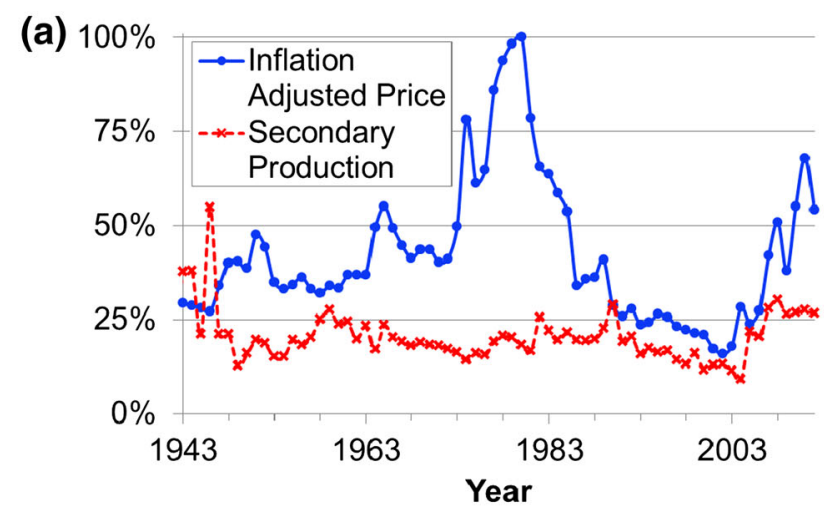

(c)

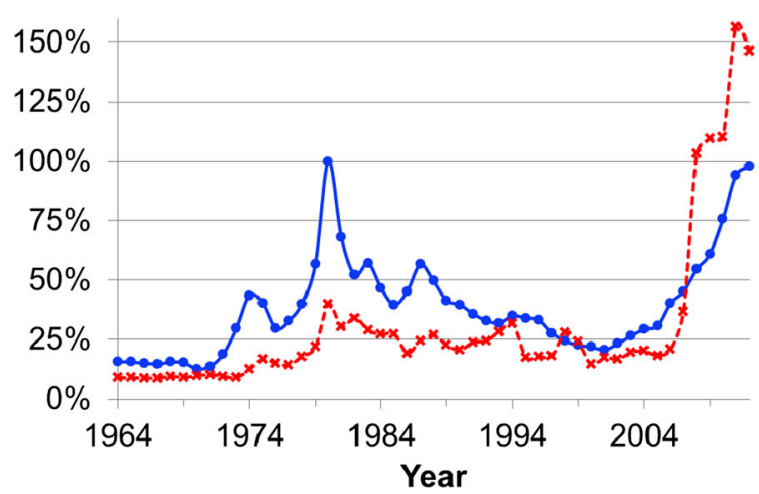

(b)

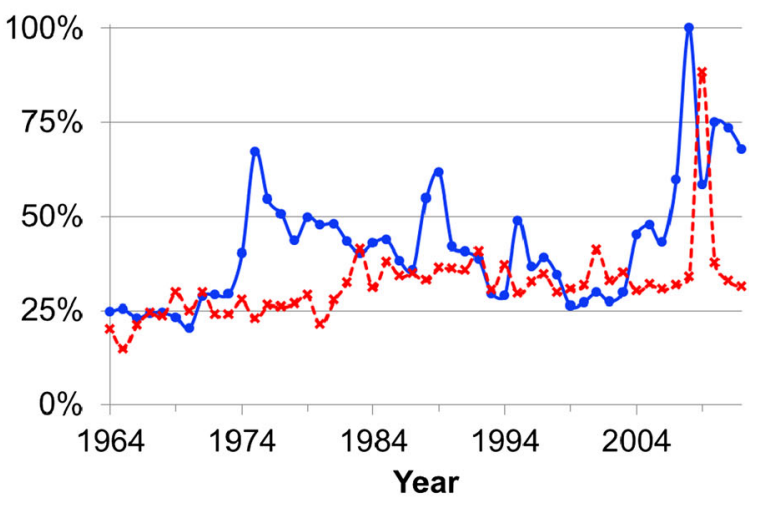

(d)

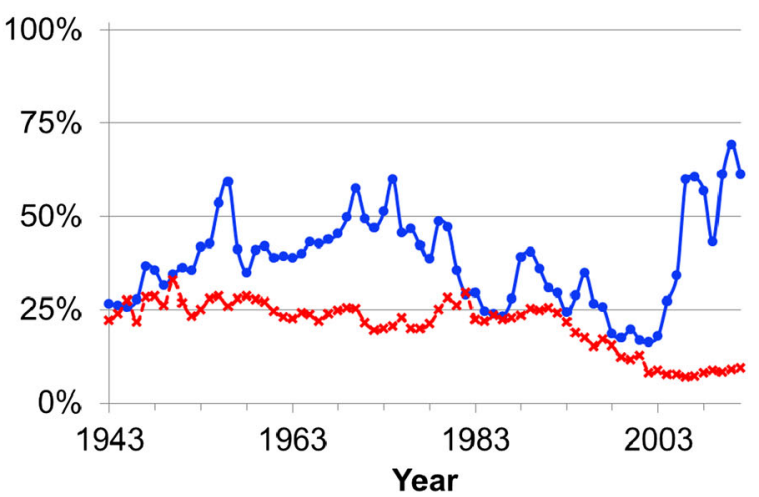

Fig. 7 Inflation-adjusted price versus secondary production rate for non-critical materials after 1939. a $\mathrm{Sn} ; \mathbf{b ~ C r} ; \mathbf{c ~} \mathrm{Au} ; \mathbf{d} \mathrm{Cu}$

correlation. Overall, we conclude from this analysis that price responses for non-critical materials are fundamentally more diverse than seen in the last section for critical materials.

\section{Expected Influence of Recycling on RE Price Development}

Based on the above analyses, several conclusions for the expected price developments of REs can be made. (i) An extensive price spike as seen for REs in 2011 has been described as the characteristic of materials becoming critical [6, 31]. Based on our analysis of historical data for other critical materials, the inflation-adjusted price for REs in the future is not expected to substantially exceed this mark. (ii) A maximum recycling rate of $42 \%$ of $\mathrm{Nd}$ is projected to be achievable in 2034 by recovering and recycling ferrous shredder scrap in the US. However, this rate is too low to have a large stabilizing effect on price volatility [27]. Based on our analysis, a much larger quantity of recycling not stemming from LDV motors or household appliances is required. Thus, end-of-life HD drives or wind generators will have to be recycled to make a sufficiently large impact on price stabilization. (iii) A relaxation of RE prices to pre-2010 levels of inflation-adjusted prices is expected to be possible, based on the historical price development of other critical materials after the criticality price spike (see Fig. 6).
While we observe a correlation between higher recycling rates and increased price stability, other factors clearly also influence price volatility, some of them political (see SI) and others revolving around market maturity. Higher recycling rates are indicative of a more mature market for the material, which in turn creates a mature market for the sale of recycled material. While other factors affect both secondary production and price stability, it is clear that high rates of recycling provide a stabilizing effect on metal prices.

\section{Summary and Conclusions}

In conclusion, we have forecasted the $\mathrm{Nd}$ content in ferrous shredder scrap during the next 20 years. Based on the obtained value of $0.33-0.97 \mathrm{~g} \mathrm{Nd} / \mathrm{kg}$ ferrous scrap in 2034 and the previously projected future demand, a maximum recycling rate of $42 \%$ of the projected total demand for $\mathrm{Nd}$ in 2034 can be expected. However, recoverability of $\mathrm{Nd}$ will depend on the treatment and future production methods of ferrous scrap. As such, it is possible that suitable feedstocks for $\mathrm{Nd}$ recovery will be located later (e.g., one potential feedstock is slag from electric arc furnaces recycling ferrous scrap $[32,33])$ or earlier in the lifecycle (e.g., by disassembly of HEV/EV motors before shredding). Our analysis of the influence of secondary 
production rates on historical price developments of other critical materials show, however, that this recycling rate might be too low to affect a significant reduction of price volatility. A recycling rate of $>50 \%$ over an extended period of time seems to be necessary to achieve that goal. Thus, the recovery of $\mathrm{Nd}$ from sources other than LDVs and household appliances will be needed to achieve price stabilization.

Acknowledgments We thank all members of the Center for Resource Recovery and Recycling for valuable discussions.

Funding Sources This work was supported by WPI, NSF (IIP$0968839+$ REU supplement), and the members of the I/UCRC Center for Resource Recovery and Recycling $\left(\mathrm{CR}^{3}\right)$.

\section{References}

1. Du X, Graedel TE (2011) Global in-use stocks of the rare earth elements: a first estimate. Environ Sci Technol 45:4096-4101. doi:10.1021/es102836s

2. Alonso E, Sherman AM, Wallington TJ, Everson MP, Field FR, Roth R, Kirchain RE (2012) Evaluating rare earth element availability: a case with revolutionary demand from clean technologies. Environ Sci Technol 46:3406-3414. doi:10.1021/ es203518d

3. China-measures related to the exportation of rare earths, tungsten, and molybdenum. World Trade Organization Website (2014) http://www.wto.org/english/tratop_e/dispu_e/cases_e/ ds431_e.htm. Accessed Aug 2014)

4. Humphries M (2013) Rare earth elements: the global supply chain; congressional research service. The Library of Congress, Washington.

5. Hitachi Group, sustainability report (2013) http://www.hitachi. com/csr/download/pdf/csr2013e.pdf Accessed Aug 2014

6. U.S. Department of Energy, Critical Materials Strategy. http:// energy.gov/sites/prod/files/DOE_CMS2011_FINAL_Full.pdf Accessed Aug 2014

7. Liu H, Zhang S, Pan D, Tian J, Yang M, Wu M, Volinsky AA (2014) Rare earth elements recycling from waste phosphor by dual hydrochloric acid dissolution. J Hazard Mater 272:96-101. doi:10.1016/j.jhazmat.2014.02.043

8. Kramer MJ, McCallum RW, Anderson IA, Constantinides S (2012) Prospects for non-rare earth permanent magnets for traction motors and generators. JOM 64:752-763. doi:10.1007/ s11837-012-0351-z

9. Grasso VB (2013) Rare earth elements in national defense: Background, oversight issues, and options for congress. Congressional Research Service. http://fas.org/sgp/crs/natsec/ R41744.pdf Accessed Aug 2014

10. Bandara HMD, Darcy JW, Apelian D, Emmert MH (2014) Value analysis of neodymium content in shredder feed: toward enabling the feasibility of rare earth magnet recycling. Environ Sci Technol 48:6553-6560. doi:10.1021/es405104k

11. Alonso E, Wallington T, Sherman A, Everson M, Field F, Roth R, Kirchain R (2012) An Assessment of the rare earth element content of conventional and electric vehicles SAE. Int J Mater Manf 5:473-477. doi:10.4271/2012-01-1061

12. U.S. Environmental Protection Agency, Light Duty Automotive Technology, Carbon Dioxide Emissions and Fuel Economy
Trends: 1975 Through 2012. http://www.epa.gov/fueleconomy/ fetrends/1975-2012/420r13001.pdf. Accessed Aug 2014

13. U.S. Department of Energy, Alternative Fuels Data Center. http:// www.afdc.energy.gov/data/10301. Accessed Aug 2014

14. Honda news releases 2013, honda established world's first process to reuse rare earth metals extracted from nickel-metal hydride batteries for hybrid vehicles. http://world.honda.com/news/ 2013/c130303Reuse-Rare-Earth-Metals/. Accessed Mar 2014

15. Cars.com, Specifications. http://www.cars.com/toyota/prius/; http://www.cars.com/honda/civic/; http://www.cars.com/ford/ focus/; http://www.cars.com/chevolet/malibu-hybrid. Accessed Aug 2014

16. U.S. Energy Information Administration, Annual Energy Outlook 2014, Data Tables, Transportation Demand Sector, Table 39. LightDuty Vehicle Sales by Technology Type-United States; http://www. eia.gov/forecasts/aeo/data.cfm\#transdemsec. Accessed Aug 2014

17. Becker TA, Sidhu I, Tenderich B. (2009) Electric vehicles in the United States: a new model with forecasts to 2030, Center for Entrepreneurship and Technology, University of California, Berkley.

18. Constantinides $\mathrm{S}$. The demand for rare earth materials in permanent magnets. 51st annual conference of metallurgists (COM), October 2012, Niagara Fallas, Canada. http://www.arnoldmag netics.com/WorkArea/DownloadAsset.aspx $? \mathrm{id}=5933$. Accessed Aug 2014

19. James A (2011) The determination of platinum group elements (PGE) and rare earth elements (REE) in waste materials by microwave digestion and ICP-MS to assess the potential for economic recovery. M. Sc. Thesis, Cranfield University, United Kingdom

20. Ongondo FO, Williams ID, Cherrett TJ (2011) How are WEEE doing? A global review of the management of electrical and electronic wastes. Waste Manag 31:714-730. doi:10.1016/j.was man.2010.10.023

21. United States geological survey, historical statistics for mineral and material commodities in the United States; U.S. Geological survey data series 140. http://minerals.usgs.gov/minerals/pubs/ historical-statistics/\#data. Accessed Aug 2014

22. Rockoff H (1984) Drastic measures: a history of wage \& price conrols in the United States. The Press Syndicate of the University of Cambridge, Cambridge

23. Krebs RE (2006) The history and use of our earth's chemical elements: a reference guide. Greenwood Press, Westport, CT

24. Ashby MF, Jones DRH (2006) Enineering materials 2: an introduction to microstructures, processing and design, 3rd edn. Elsevier Linacre House, Jordan Hill, Oxford

25. Report on critical raw materials for the EU. Critical raw materials profiles (2014). http://ec.europa.eu/enterprise/policies/raw-mate rials/files/docs/crm-critical-material-profiles_en.pdf. Accessed Aug 2014

26. United States geological survey, metal prices in the united states through 2010; Scientific investigations report 2012-5188. http:// pubs.usgs.gov/sir/2012/5188/. Accessed Aug 2014

27. Alonso E, Field FR, Roth R, Kirchain RE (2009) Strategies to address risks of platinum scarcity for supply chain downstream firms. IEEE International Symposium on Sustainable Systems and Technology, Phoenix

28. UNEP (2011), Recycling rates of metals - a status report, a report of the working group on the global metal flows to the international resource panel. Graedel TE, Allwood J, Birat J.-P, Reck B.K, Sibley S.F, Sonnemann G. www.unep.org/resourcepanel/ Portals/24102/PDFs/Metals_Recycling_Rates_110412-1.pdf. Accessed Aug 2014

29. Rademaker JH, Kleijn R, Yang Y (2013) Recycling as a strategy against rare earth element criticality: a systemic evaluation of the 
potential yield of NdFeB magnet recycling. Environ Sci Technol 47:10129-10136. doi:10.1021/es305007w

30. Emmert MH, Bandara HMD (2015) Rare Earth Recycling. U.S. Patent Application No. 62103661, 15 Jan 2015

31. Bujis B, Sievers H, Espinoza LAT (2012) Limits to the critical raw materials approach. Proc ICE-Waste Resour Manag 65:201-208. doi:10.1680/warm.12.00010

32. Nakajima K, Takeda O, Miki T, Matsubae K, Nakamura S, Nagasaka T (2010) Thermodynamic analysis of contamination by alloying elements in aluminum recycling. Environ Sci Technol 44:5594-5600. doi:10.1021/es9038769

33. Bandara HMD, Mantell MA, Darcy JW, Emmert MH (2015)

Closing the lifecycle of rare earth magnets: discovery of neodymium in slag from steel mills. Energy Technol 3:118-120. doi:10.1002/ente.201402162 